\title{
A Strategic Organisational Perspective of Industry 4.0: A Conceptual Model
}

\author{
Stefan Smuts ${ }^{(\varpi)}(\mathbb{D}$, Alta van der Merwe (D), and Hanlie Smuts (iD \\ Department of Informatics, University of Pretoria, Pretoria, South Africa \\ sbsmuts@gmail.com, \{alta, hanlie.smuts\}@up.ac.za
}

\begin{abstract}
The so-called fourth industrial revolution or Industry 4.0 (I4.0), with its potentially disruptive technologies, is changing the way we socialise, live and work and provides opportunities for organisations to innovate and disrupt. Although organisations are acknowledging the emergence of I4.0 and realise the importance of being ready for its impact, better understanding is required of the potential of I4.0 and its holistic impact on organisations. In this paper, we conducted a systematic literature review to identify all I4.0-related organisational aspects, such as an I4.0-relevant strategy, digital business model innovation, technology investment optimisation, workforce management complexity, digital eco-systems, technology-centric convergence, virtual model and physical environment linkage, value chain digitalisation and product portfolio innovation. Furthermore, we presented these I4.0 organisational aspects identified in a conceptual model based on the components of organisational strategic alignment. By using such a conceptual model, organisations can ensure that both optimisation and new opportunities enabled by I4.0 are leveraged and that a relevant, strategically aligned approach to I4.0 may be considered.
\end{abstract}

Keywords: Industry 4.0 - Fourth industrial revolution - Strategic alignment • Organisational context $\cdot$ Conceptual model

\section{Introduction}

The term Industry 4.0 was formalised in 2011 in Germany at the Hannover Messe [13]. Industry 4.0 or the fourth industrial revolution is marked by a fast change in technologies that are changing the way we socialise, live and work [4]. Disruptive technologies emerging from I4.0, such as the internet of things (IoT), internet of services and cyber-physical systems (CPS), present new ways in which organisations can conduct business [5]. Organisations require a detailed strategic and technological plan to optimise the benefits of I4.0 and to become digital organisations [6, 7].

Although the term I4.0 is used in an organisational context, there is no accepted definition for I4.0 [4, 7-10]. Bär et al. [4] classified I4.0 as a rapid change in technology, whereas Geißler et al. [11] associated I4.0 with certain technological advancements such as IoT and CPS. Badri et al. [1] and Lezzi et al. [12] take a different view and propose that I4.0 refers to the unity of the manufacturing industry with socalled smart technologies such as IoT and CPS. Further definitions of I4.0 include "cutting-edge and disruptive technologies" [13], "end-to-end digitisation of all physical 
assets and processes" [14] and "sum of all disruptive innovations derived and implemented in a value chain to address the trends of digitalization" [8]. We need to understand what the unique I4.0 organisational aspects are and consider how these unique aspects affect strategic alignment in organisations. Therefore, the focus of this paper is on contributing to the discourse on what I4.0 is from an organisational perspective, by considering the following research question: "What are the unique I4.0 organisational aspects and how do these unique aspects affect strategic alignment in an organisation?" We reflect on this research question by considering an overview of I4.0, by understanding the nature of I4.0 in an organisational context and by considering the impact of strategic alignment.

In this paper we firstly provide an overview of literature in Sect. 2, followed by the research approach in Sect. 3. In Sect. 4 we present a discussion on the data analysis and findings, while Sect. 5 details the contribution of the study. Section 6 concludes the paper.

\section{Background}

Scholars report on four major industrial revolutions. As early as the $18^{\text {th }}$ century, the first industrial revolution occurred [5]. With the introduction of steam-powered machines, production was decoupled from the physical limitations of humans. In the $19^{\text {th }}$ century, the introduction of electricity created faster and more compact machines, leading to the second industrial revolution. The third industrial revolution was marked by the development of electronic circuits leading to assembly lines becoming more and more automated. Automation presented opportunities for optimisation of machines and processes [5]. The I4.0 is a relatively new concept first mentioned in Germany in 2011 and contrary to the other three industrial revolutions, its impact is not yet fully known $[2,7,9]$. The focus on connectivity and communication makes I4.0 intrinsically different from the other three industrial revolutions [15]. In Sect. 2.1 we give a short introduction on what I4.0 is, followed by Sect. 2.2, where we consider the organisational context of I4.0, and Sect. 2.3, in which we discuss strategic alignment.

\subsection{Overview of $\mathbf{I} 4.0$}

The world is experiencing revolutionary advances in science and technology [16]. In a progressively digital world, organisations have invested significantly in technologies to keep ahead of competitors and potential disruptors [17]. First-order disruption includes localised change within a market, where a particular technology is disruptive. Secondorder disruption influences many industries and substantially changes societal norms and institutions, where technologies disrupt social interactions and relationships, organisational structures, institutions and public policies [18]. The aim of I4.0 is to realise improved operational efficiency and productivity [19]. This could be achieved through features such as digitisation, optimisation, production customisation, automation and adaptation [19, 20]. Furthermore, human-machine interaction enables enhanced value-added services, automatic data exchange and communication [20]. These features are also strongly associated with industrial value-adding processes, 
knowledge management, internet technologies and advanced algorithms [20] and applied across three areas of impact, namely integration of value chains (e.g. IoT, cloud computing, etc.), digitisation of offerings (e.g. augmented reality, smart sensors, big data analytics), and digital business models and customer access (e.g. authentication, artificial intelligence, etc.) [21, 22].

\subsection{Organisational Context of $\mathbf{I 4 . 0}$}

In order to realise I4.0 alignment, organisations need to manage multiple internal and external factors to enhance business value and create a sustainable competitive advantage [23]. Specific factors include horizontal, vertical and digital integration and areas of standardisation enabling organisations to connect to one another easily [24]. Organisations will have to manage multiple complexities, namely complex systems, as it is required to develop and apply new models and methods [25]; comprehensive infrastructure consisting of a high-quality information network and internet connectivity; security and privacy, enforcing data protection [12]; work organisation and design, as the roles of the employees change [26]; new and relevant legal frameworks [1] and the effective use of resources [24]. Organisational performance in this new era requires managing teams of highly specialised technical experts, as well as employees trained to operate in the new technological revolution, with specific profiles that are currently non-existent $[27,28]$. In the next section we consider strategic alignment in organisations.

\subsection{Strategic Alignment in Organisations}

Organisations employ strategic planning to define direction and to guide decisions on resource allocation to pursue their strategy [29, 30]. Strategic planning provides a sense of direction, outlines measurable goals in an organisation and guides day-to-day decisions [29]. Furthermore, strategic planning is concerned with the definition of changes that may be informed by changing market conditions, competitor activity and technology advancement - typically aspects encompassed by I4.0 [29, 31]. For organisations to manage all the multiple internal and external factors described in the previous section strategically, strategic alignment must be achieved at both enterprise and departmental level [32], across four domains of strategic choices, namely strategy execution, technology potential, competitive potential and service level [31]. Strategy execution refers to business strategy as a driver of both organisational design choices and information system infrastructure, while technology potential involves the articulation of an information technology strategy in support of the selected business strategy $[31,32]$. Competitive potential as alignment perspective is concerned with the exploitation of emerging information technology capabilities that affect key attributes of strategy, such as distinctive competencies, and it has an impact on business scope, such as new products and services, and business governance, which includes the development of new forms of relationships [31,32]. The service level focuses on establishing a world-class technology organisation within an organisation and focuses on the effective use of IS resources, as well as responsiveness to the fast-changing demands of end-users and customers [31, 32]. Achieving and sustaining strategic 
alignment in organisations are influenced by a rapidly changing operating environment enabled by I4.0 aspects such as workforce skills and change capacity, business process automation, multiplicity of digital business models, and the variety and expectations of different customer segments [30, 32]. Therefore, I4.0 aspects must be considered across all four domains of strategic choices to achieve strategic alignment [29, 31].

\section{Research Approach}

The objective of this paper is to present the unique I4.0 organisational aspects, including the way in which these unique aspects affect strategic alignment in an organisation. In order to achieve the objective, a systematic literature review (SLR) was conducted to identify the components of a guiding conceptual model [33, 34]. The aim of an SLR is to gather, evaluate and synthesise the existing body of completed and recorded work produced by researchers, scholars and practitioners [34]. An SLR must be conducted based on a rigorous, stand-alone and systematic methodological approach $[33,35]$. Specifically, we followed the methodological approach suggested by Boland, Cherry and Dickson [36], consisting of three main stages: planning the review (defining the research objectives and the review protocol), conducting the review (selecting the primary studies and extracting the data) and reporting the review (disseminating the report) $[35,37]$. Technical reports, books and specific scientific databases were chosen for the SLR process. The databases presented in Table 1 provided access to highquality peer-review content and were therefore chosen for the SLR. I4.0 is known by many terms, including 4IR and the 'fourth industrial revolution'. To include all references to I4.0, the search terms were chosen as: "4ir and "strategic alignment" and organisation", "fourth industrial revolution" and "strategic alignment" and organisation" and "I4.0" and "strategic alignment" and organisation". Using all the search terms listed and only including sources from 2011 onwards, as this was the date when the term I4.0 originated, a result set of 301 papers was identified, as shown in Table 1.

Table 1. Total number of papers found per database

\begin{tabular}{l|l|l}
\hline Database & $\begin{array}{l}\text { Total papers found matching } \\
\text { keywords }\end{array}$ & $\begin{array}{l}\text { Total after first inclusion and exclusion } \\
\text { criteria }\end{array}$ \\
\hline ScienceDirect & 97 & 32 \\
\hline SpringerLink & 64 & 22 \\
\hline EBSCOhost & 31 & 16 \\
\hline IEEE Xplore & 9 & 5 \\
\hline Emerald & 100 & 29 \\
Insight & & 104 \\
\hline Total & 301 &
\end{tabular}

The initial research studies extracted (301) were screened by applying specific criteria such as non-English studies, anecdotal or opinion-based papers, unobtainable papers and duplicate studies that formed part of the result set. Inclusion criteria 
consisted of peer-reviewed publications and technical reports relevant to the research question. After the initial search, as well as the application of inclusion and exclusion criteria, 104 publications were selected (Table 1 last column). We concluded a detailed screening of abstracts and analysis of the full text of the prospective papers, after which 35 papers were coded and themed. Sixty-nine papers were excluded based on criteria such as studies not associated with the research question, theses or dissertations and a keyword mismatch, e.g. where both "industry" and "4" appeared in a paper, but in an unrelated context.

\section{Data Analysis and Findings}

The aim of this paper is to consider the unique I4.0 organisational aspects and to reflect on the impact of these unique aspects on strategic alignment in organisations. Themes and main themes were identified in the selected studies through a two-step process: firstly, descriptive codes were used to identify themes [38] and secondly, open coding was used to identify emerging main themes [39]. Table 2 depicts the emerging themes and main themes, as well as the reference.

The first emerging theme is external drivers, i.e. drivers external to the organisation related to the job market and the particular market and industry sector. It is acknowledged that I4.0 may create new jobs and change current jobs to the extent that employees must either be retrained or upskilled. Job market disruptions may enforce greater worker independence, require increased workforce cognitive load, necessitate workforce augmentation and emphasise increased autonomy. Another external factor is global market and industry sector disruption. Organisations are forced to meet the everchanging demand of consumers and must navigate the transformation of the market, industry and business sectors. Traditional markets and industries are challenged by innovations and an increased rate of change in technology. At a strategic level, organisations need to consider an I4.0-relevant strategy. Such a strategy brings about a potential competitive advantage gain, additional organisational value creation, organisational agility enablement and strategic objective optimisation. New technology changes the rules of the global market and therefore organisations are empowered to create new business value. As organisations embrace the new strategies and agility, there may be an organisational structural alignment trade-off where particular internal structures need to be revised to carry out the I4.0 relevant strategy. The business value theme highlights opportunities for business improvement, whether it is internally focused (increased effectiveness and efficiency) or related to digital business model innovation (harnessing I4.0 technologies). Internal effectiveness and efficiency improvement are fundamentally based on the value capitalisation of knowledge held in the organisation, while digital business model innovation may inherently be based on technology investment optimisation. The workforce emerging theme is internally focussed and deals specifically with the transformative and disruptive nature of I4.0 on the workforce of an organisation. The impact of this includes not only environmental innovation potential, productivity improvement, required skills, and education alignment, but also management complexity and workforce well-being. Complexity is 
created as managers must now manage teams with different skills, in agile and fastpaced environments requiring socially sustainable work systems, as well as agile environmental change response. As there is greater emphasis on collaboration and transparency, organisations must consider workplace ergonomics, workforce flexibility and motivation, change appetite and the impact on governance. Digital technologies enable environments in which workforce productivity can be improved through automation with a consequent impact on role and responsibility definition. Furthermore, productivity changes require a different skill mix, demanding essential problemsolving, critical thinking and design thinking abilities.

Table 2. I4.0 aspect themes and sub-themes extracted

\begin{tabular}{|c|c|c|}
\hline Main theme & Theme & References \\
\hline \multirow[t]{2}{*}{ External drivers } & Job market disruption & {$[5,22,40-44]$} \\
\hline & Market and industry disruption & {$[1,4,13,14,26,42-47]$} \\
\hline \multirow{5}{*}{$\begin{array}{l}\text { I4.0 relevant } \\
\text { strategy }\end{array}$} & Competitive advantage gain & {$[4,6]$} \\
\hline & Organisational agility enablement & {$[5,7,22,26,45]$} \\
\hline & $\begin{array}{l}\text { Organisational structural alignment trade- } \\
\text { offs }\end{array}$ & {$[26,45,46]$} \\
\hline & Organisational value creation & {$[26,45]$} \\
\hline & Strategic objective optimisation & {$[6,7,12,14,42,46]$} \\
\hline \multirow[t]{5}{*}{ Business value } & Business opportunity improvement & {$[4,7,12,45,48]$} \\
\hline & Digital business model innovation & $\begin{array}{l}{[4,5,7,8,11,13,22} \\
26,42,46,47]\end{array}$ \\
\hline & Increased entrepreneurial activity & {$[43,47,49]$} \\
\hline & Knowledge management value capitalisation & {$[10,25,42]$} \\
\hline & Technology investment optimisation & {$[40,45]$} \\
\hline \multirow[t]{6}{*}{ Workforce } & Work environment innovation & {$[1,13,25,41,45]$} \\
\hline & Workforce education alignment & {$[1,13,22,25,44,46]$} \\
\hline & Workforce management complexity & $\begin{array}{l}{[1,5,7,13,22,25,41,} \\
42,44,46]\end{array}$ \\
\hline & Workforce productivity improvement & {$[12,25,41]$} \\
\hline & Workforce skills qualification & {$[1,5,25,40-44,46]$} \\
\hline & Workforce well-being improvement & {$[5,41]$} \\
\hline \multirow[t]{4}{*}{ Technology } & Digital eco-systems & $\begin{array}{l}{[3,7,8,12,13,22,25,} \\
46,48,50-52]\end{array}$ \\
\hline & $\begin{array}{l}\text { Information technology security } \\
\text { consideration }\end{array}$ & {$[42]$} \\
\hline & Technology-centric convergence & {$[5,12,15,25,26,42]$} \\
\hline & $\begin{array}{l}\text { Virtual model and physical environment } \\
\text { linkage }\end{array}$ & {$[1,7,22,25,41,50]$} \\
\hline
\end{tabular}


Table 2. (continued)

\begin{tabular}{|c|c|c|}
\hline Main theme & Theme & References \\
\hline \multirow[t]{2}{*}{ Customer value } & Customer experience differentiation & {$[4,26,46]$} \\
\hline & $\begin{array}{l}\text { Customer-organisation interaction } \\
\text { improvement }\end{array}$ & {$[4]$} \\
\hline \multirow[t]{2}{*}{ Process } & Process optimisation & $\begin{array}{l}{[3,4,7-9,22,25,40} \\
42,44-46,53-55]\end{array}$ \\
\hline & Value chain digitalisation & {$[1,4,45,48]$} \\
\hline \multirow[t]{3}{*}{ Data } & Big data management & $\begin{array}{l}{[3,9,13,22,25,42,51,} \\
53]\end{array}$ \\
\hline & Data-driven decision-making & {$[1,8,10,12,25,42,53]$} \\
\hline & Product and process big data generation & {$[11,12]$} \\
\hline \multirow{3}{*}{$\begin{array}{l}\text { Organisational } \\
\text { change }\end{array}$} & Human-centric design transformation & {$[7,8,25,40,41,53]$} \\
\hline & Organisational culture change expectations & {$[44]$} \\
\hline & $\begin{array}{l}\text { Tension impact of emerging versus legacy } \\
\text { infrastructures }\end{array}$ & {$[7,26]$} \\
\hline \multirow[t]{2}{*}{ Product } & Product customisation & {$[3,45,50]$} \\
\hline & Product portfolio innovation & $\begin{array}{l}{[3-11,13,40,42,43} \\
46,48,50,53]\end{array}$ \\
\hline
\end{tabular}

From a technology perspective, digital eco-systems are enabled where strategy, channels, people and technology are connected within an organisation or across multiple organisations in the eco-system, emphasising security implementation concerns. As the digital technologies inform change, transformation may be based on technologycentric convergence, especially in instances where there is a blurring between virtual and physical worlds (digital twins) or where the digital world is translated to the physical one (3D printing). Customer value, the manner in which it is defined and how organisations view it, is centred on customer experience and the interaction between the organisation and the customer. Exceptional customer experience not only creates satisfied customers, but also leads to a competitive advantage gain. As more organisations adapt to I4.0, differentiating factors between organisations are dependent on customer experience, as improved customer satisfaction attracts more customers and retains existing ones. I4.0 presents opportunities for organisations not only to optimize their processes, but also to digitise their entire value chain. Changes such as manufacturing process automation and digitisation can boost manufacturing efficiency. Technologies of I4.0 can enable innovation and adoption of business processes, as well as automation of work processes. Digitisation of products, processes and systems allows organisations to gain better insight into their business operations, leading to accuracy and precision improvements, preventive step monitoring and automation of information technology innovations. Integration with the processes of other organisations becomes possible, creating improved cross-function and eco-system collaborations. Better processes lead to the evolution of business analytics and implications for lean practices. 
Large volumes of data are one of the key characteristics of I4.0. Big data management enabling data-driven decision-making, as well as product- and process-related big data generation, requires organisations to build capabilities to process vast amounts of data. Not only must big datasets be collected by an organisation, but these datasets also need to be converted, harnessed and interpreted in near-real time in order to generate relevant insights. Furthermore, process- and product-related data analysis informs process automation opportunities, enabling advantages such as service level improvement, inventory reduction and shorter time to market. Technologies such as CPS and IoT can be used to monitor production lines and product quality. However, organisations must be aware of the impact on computational power that data-driven decision-making requires, as well as the governance, security and management of such collected data. Organisational change has an impact on several levels; firstly, the organisation must migrate from legacy technology to future technology with consequent impacts on processes, products, data and the workforce. New technologies create new avenues for organisations to pursue new and better products through product customisation and product portfolio innovation. Organisations must cater not only for the needs of the individual customer, but also encourage customer collaboration as well as creating opportunities for quality, customised products. Such flexible product portfolios offer a competitive edge, while product design, planning and production are becoming more customised as well. Product lines experience short production lifecycle changes often enabled by robotisation. However, this will require organisation of wideranging changes in manufacturing operations and technology, providing opportunities for product and device miniaturisation, production of products via advanced ICT and product-tracking possibilities.

\section{An I4.0 Conceptual Model}

Using the themes derived during the thematic analysis (Table 2) and the strategic alignment domains (Sect. 2.3), the I4.0 aspects derived were arranged in a conceptual model from an organisational perspective depicted in Fig. 1.

The conceptual model is built across the four domains of strategic choices, namely strategic execution, technology potential, competitive potential and service level (Sect. 2.3). The strategy execution domain employs business strategy as a driver of both organisational design choices and information systems infrastructure. Under strategic execution, organisations must focus on external factors, I4.0-relevant strategy and business value. Organisations need to be aware of any I4.0-induced external factors that can affect the organisation. Factors such as job market disruptions or market and industry disruption may present great opportunities for growth. As organisations change to I4.0-ready organisations, they need to be guided by an I4.0relevant strategy. This strategy ensures future sustainability of an organisation in a global market potentially disrupted by I4.0. New processes, technology and markets have redefined business value in an I4.0-driven society. Organisations must reconsider business value, whether the focus is outward towards the customer or based on internal optimisation and automation, and adjust strategies accordingly. 


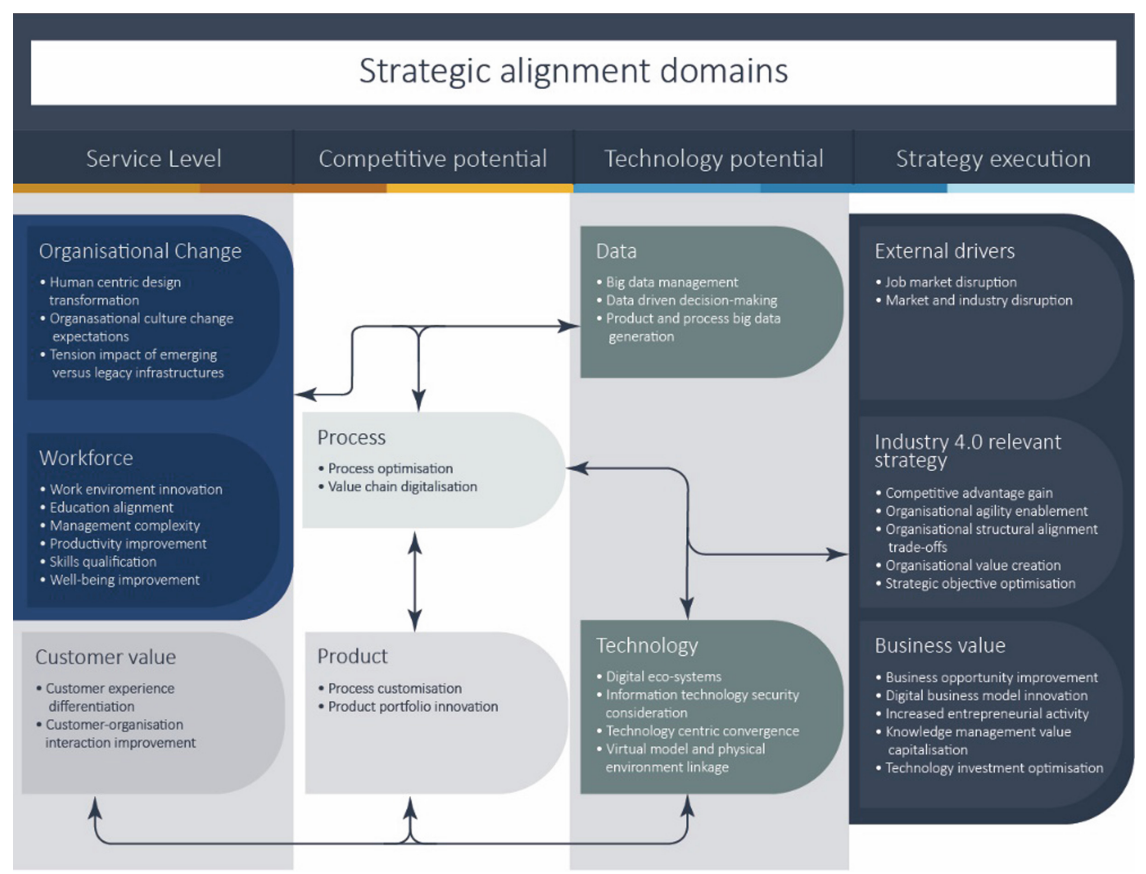

Fig. 1. Strategic organisational perspective of I4.0 aspects (adapted from [31])

The technology potential domain refers to the information technology strategy that supports the selected business strategy by considering the technologies of I4.0 and data. The disruptive nature and technologies of I4.0 force organisations to move towards new technologies to ensure future sustainability and competitiveness. Big data and data-driven decision-making create new opportunities for organisations to collect, analyse and use data. Data have a direct impact on customer value, in terms of information collected and analysed, and inform products and processes. The competitive potential domain as alignment perspective emphasises the use of emerging information technology capabilities that influence the business scope, such as new products and services. The product market is constantly innovating and implementing customisation for the individual. Organisations must adapt to this demand with innovations in products and processes, as well as consideration of the individual's need. Process organisations are continually optimised and digitised. This allows organisations to get products and services to market faster; however, organisations need to adopt better processes to stay competitive.

Lastly, the service level domain attends to establishing a world-class technology organisation within an organisation and focuses not only on the effective use of IS resources, but also on responsiveness to the fast-changing demands of end-users and customers. The technology and changes that come with I4.0 force the workforce to adapt in terms of productivity, skills and well-being. With new technologies and business models emerging, the focus of customer value is also shifting. I4.0 demands 
greater focus on customer interaction and experience. With the disruptive nature of I4.0 having a global impact, organisations must change to stay competitive or to re-invent themselves. Organisations must also be able to manage the tension impact of emerging versus legacy infrastructures.

These four strategic alignment domains also present interrelationships (denoted by arrows), as the business strategy informs the technology aspect, focusing on implementing the chosen business strategy and recognising the need to address both external and internal domains [31]. The chosen business strategy and technology opportunity also affect decisions such as product-market offering and choices pertaining to the organisational structure and workforce, as well as the specific rationale for the design and redesign of critical business processes [31].

\section{Conclusion}

I4.0 and the advancement of digital technologies are changing the way we socialise, live and work. I4.0 also provides organisations with opportunities to firstly optimise and enhance internal operations and secondly, innovate and optimise business models. It is important that organisations understand the realities of I4.0, in order to exploit its business value in an organisational context, while maintaining strategic alignment. In this study, the unique I4.0 organisational aspects were identified through an SLR related to digital business model innovation, technology investment optimisation, workforce management complexity, digital eco-systems, technology-centric convergence, virtual model and physical environment linkage, value chain digitalisation and product portfolio innovation. In order to apply these I4.0 organisational aspects, we propose a conceptual model guiding organisations on how these unique aspects affect strategic alignment in an organisation. By applying the proposed conceptual model of I4.0, a strong vision, support- and development plan and path to I4.0 can be created. By understanding such a view of I4.0, organisations can ensure that interrelationships are managed and that a relevant, fit-for-purpose approach to I4.0 may be considered in a strategically aligned manner.

As the study proposes a conceptual model, further research may be conducted to test the proposed strategic alignment model in an organisational context and real-world scenario.

\section{References}

1. Badri, A., Boudreau-Trudel, B., Souissi, A.S.: Occupational health and safety in the industry 4.0 era: a cause for major concern? Saf. Sci. 109, 403-411 (2018)

2. Ding, B.: Pharma Industry 4.0: literature review and research opportunities in sustainable pharmaceutical supply chains. Process Saf. Environ. Prot. 119, 115-130 (2018)

3. Rajput, S., Singh, S.P.: Current trends in Industry 4.0 and implications in container supply chain management: a key toward make in India. In: Digital India, pp. 209-224 (2018)

4. Bär, K., Herbert-Hansen, Z.N.L., Khalid, W.: Considering Industry 4.0 aspects in the supply chain for an SME. Prod. Eng. 12(6), 747-758 (2018) 
5. Gerryts, E.W., Maree, J.G.: Enhancing the employability of young adults from socioeconomically challenged contexts: theoretical overview. In: Maree, Jacobus G. (ed.) Handbook of Innovative Career Counselling, pp. 425-444. Springer, Cham (2019). https:// doi.org/10.1007/978-3-030-22799-9_24

6. Özdağoğlu, A., et al.: A predictive filtering approach for clarifying bibliometric datasets: an example on the research articles related to industry 4.0. Technol. Anal. Strateg. Manage. (2019). https://doi.org/10.1080/09537325.2019.1645826

7. Ghobakhloo, M.: The future of manufacturing industry: a strategic roadmap toward Industry 4.0. J. Manuf. Technol. Manage. 29(6), 910-936 (2018)

8. Pfohl, H., Yahsi, B., Kurnaz, T.: The impact of Industry 4.0 on supply chain. In: Kersten, W., Blecker, T., Ringle, C. (eds.) Innovations and Strategies for Logistics and Supply Chains, pp. 31-58 (2015)

9. Cieśla, B., Kolny, D.: Visual process analysis in SMEs as a support for management models on example of TOC. J. Syst. Integr. 10(2), 19-27 (2019)

10. Junior, C.H., et al.: Performance, farmer perception, and the routinisation (RO) moderation on ERP post-implementation. Heliyon 5(6), 1-13 (2019)

11. Geißler, A., et al.: Structuring the anticipated benefits of the fourth industrial revolution. In: Twenty-Fifth Americas Conference on Information Systems, Cancun (2019)

12. Lezzi, M., Lazoi, M., Corallo, A.: Cybersecurity for Industry 4.0 in the current literature: a reference framework. Comput. Ind. 103, 97-110 (2018)

13. Frederico, G.F., et al.: Supply chain 4.0: concepts, maturity and research agenda. Supply Chain Manag. Int. J. (2019)

14. Turcu, C.O., Turcu, C.E.: Industrial Internet of Things as a challenge for higher education. Int. J. Adv. Comput. Sci. Appl. 9(11), 55-60 (2018)

15. Karjalainen, J., Heinonen, S., Shaw, M.: Peer-to-peer and circular economy principles in the fourth industrial revolution (4IR) - new risks and opportunities. In: 2019 International Conference on the Domestic Use of Energy (DUE) (2019)

16. Tabarés, R.: Harnessing the power of digital social platforms to shake up makers and manufacturing entrepreneurs towards a european open manufacturing ecosystem, R.a.I. Action, Editor (2016)

17. Rocha, L., et al.: Cloud management tools for sustainable SMEs. Procedia CIRP 40, 220224 (2016)

18. Schuelke-Leech, B.: A model for understanding the orders of magnitude of disruptive technologies. Technol. Forecast. Soc. Change 129(C), 261-274 (2018)

19. Lu, Y.: Industry 4.0: a survey on technologies, applications and open research issues. J. Ind. Inf. Integr. 6, 1-10 (2017)

20. Roblek, V., Meško, M., Krapež, A.: A complex view of Industry 4.0. SAGE Open 6(2), 111 (2016)

21. Khairuddin, S.M., Omar, F.I., Ahmad, N.: Digital inclusion domain in entrepreneurship: a preliminary analysis. Adv. Sci. Lett. 24, 2721-2724 (2018)

22. Wagire, A.A.W., Rathore, A.P.S., Jain, R.: Analysis and synthesis of Industry 4.0 research landscape using latent semantic analysis approach. J. Manuf. Technol. Manag. (2018)

23. Chen, J., Yin, X., Mei, L.: Holistic innovation: an emerging innovation paradigm. Int. J. Innov. Stud. 2(1), 1-13 (2018)

24. Crnjac, M., Veža, I., Banduka, N.: From concept to the introduction of Industry 4.0. Int. J. Ind. Eng. Manag. (IJIEM) 8(1), 21-30 (2017)

25. Pinzone, M., et al.: A framework for operative and social sustainability functionalities in Human-Centric Cyber-Physical Production Systems. Comput. Ind. Eng. (2018) 
26. Karodia, N.C.: Managing the transition to a 'digital culture': the experience of financial service firms. In: Gordon Institute of Business Science. University of Pretoria, Pretoria, p. 107 (2018)

27. Gareis, K., et al.: E-skills for jobs in Europe: measuring progress and moving ahead (2014)

28. O'Connor, B.: Digital transformation a framework for ICT literacy. In: A Report of the International ICT Literacy Panel (2007)

29. Lawrie, G., et al.: Multi-level strategic alignment within a complex organisation. J. Model. Manage. 11(4), 889-910 (2016)

30. Kaplan, R.S., Norton, D.P.: Strategy Maps: Converting Intangible Assets Into Tangible Outcomes. Harvard Business School Publishing Corp., Boston (2004)

31. Reksoatmodjo, W., et al.: Exploratory study on alignment between IT and business strategies. Gadjah Mada Int. J. Bus. 14(2), 139-162 (2012)

32. Trevor, J., Varcoe, B.: Strategy: how aligned is your organization? Harvard Bus. Rev. 1-6 (2017)

33. Biolchini, J., et al.: Systematic review in software engineering. In: System Engineering and Computer Science Department, PESC, Rio de Janeiro (2005)

34. Rouhani, B.D., et al.: A systematic literature review on enterprise architecture implementation methodologies. Inf. Softw. Technol. 2015(62), 1-20 (2015)

35. Aromataris, E., Pearson, A.: The systematic review: an overview. AJN Am. J. Nurs. 114, 53-58 (2014)

36. Boland, A., Cherry, M.G., Dickson, R.: Doing a Systematic Review: A Student's Guide. SAGE Publications, London (2014)

37. Rouhani, B.D., et al.: A systematic literature review on enterprise architecture implementation methodologies. Inf. Softw. Technol. 62, 1-20 (2015)

38. Welman, C., Kruger, F., Mitchell, B.: Research Methodology, 3rd edn. Oxford University Press Southern Africa, Cape Town (1994)

39. Leedy, P.D., Ormrod, J.E.: Practical Research: Planning and Design, 10th edn. Pearson Education Limited, New Jersey (2014)

40. Issa, A., et al.: Open innovation in the workplace: future work lab as a living lab. Procedia CIRP 72, 629-634 (2018)

41. Kadir, B.A., Broberg, O., Conceição, C.S.d.: Current research and future perspectives on human factors and ergonomics in Industry 4.0. Comput. Ind. Eng. 137 (2019)

42. Canetta, L., Barni, A., Montini, E.: Development of a digitalization maturity model for the manufacturing sector. In: 2018 IEEE International Conference on Engineering, Technology and Innovation (ICE/ITMC) (2018)

43. Ho, Y.F., Turner, J.J.: Entrepreneurial learning'- the role of university led business incubators and mentors in equipping graduates with the necessary skills set for Industry 4.0. Int. J. Educ. Psychol. Couns. 4(30), 283-298 (2019)

44. Scavarda, A., et al.: An analysis of the corporate social responsibility and the Industry 4.0 with focus on the youth generation: a sustainable human resource management framework. Sustainability 11, 1-20 (2019). 5130

45. Ooi, K.-B., et al.: Cloud computing in manufacturing: the next industrial revolution in Malaysia? Expert Syst. Appl. 93, 376-394 (2018)

46. Prifti, L.: Professional qualification in "Industrie 4.0": building a competency model and competency-based curriculum. In: Faculty Informatics. Technischen Universität München, p. 258 (2019)

47. Müller, M., Vorraber, W., Slany, W.: Open principles in new business models for information systems. J. Open Innov. Technol. Market Complex. 5(6), 1-13 (2019)

48. Ferreira, F., et al.: Industry 4.0 as enabler for effective manufacturing virtual enterprises. In: Collaboration in a Hyperconnected World, pp. 274-285 (2016) 
49. Liu, Z., Stephens, V.: Exploring innovation ecosystem from the perspective of sustainability: towards a conceptual framework. J. Open Innov. Technol. Market Complex. 5(48), 1-14 (2019)

50. Illmerab, B., Vielhaberb, M.: Virtual validation of decentrally controlled manufacturing systems with cyber-physical functionalities. Procedia CIRP 72, 509-514 (2018). L. Wang, Editor

51. Mourtzis, D., Vlachou, E., Milas, N.: Industrial big data as a result of IoT adoption in manufacturing. Procedia CIRP 55, 290-295 (2016)

52. Tasleem, M., Khan, N., Nisar, A.: Impact of technology management on corporate sustainability performance: the mediating role of TQM. Int. J. Qual. Reliab. Manage. 36(9), 1574-1599 (2019)

53. Gupta, A., Modgil, S., Gunasekaran, A.: Big data in lean six sigma: a review and further research directions. Int. J. Prod. Res. (2019). https://doi.org/10.1080/00207543.2019. 1598599

54. Daú, G., et al.: The healthcare sustainable supply chain 4.0: the circular economy transition conceptual framework with the corporate social responsibility mirror. Sustainability 11, 1-19 (2019). 3259

55. Syama, N., Sharmab, A.: Waiting for a sales renaissance in the fourth industrial revolution: machine learning and artificial intelligence in sales research and practice. Ind. Mark. Manage. 2018(69), 135-146 (2018) 